Józef Stala

The Pontifical University of John Paul II in Cracow, Poland

\title{
Rezension \\ Stanisław Sojka, CONTEMPLATIO ET IMITATIO CHRISTI. Chrystologiczny wymiar kontemplacji i naśladowania w duchowości chrześcijańskiej według współczesnego nauczania Kościoła, Kraków 2006
}

(Stanisław Sojka, CONTEMPLATIO ET IMITATIO CHRISTI. Die christologische Dimension von Kontemplation und Nachfolge im christlichen Geist nach der kirchlichen Lehre in der Gegenwart, Krakau 2006),Verlag der Unbeschuhten Karmeliter, 525 Seiten, ISBN 83-7305-186-4

Im „Katechismus der Katholischen Kirche” lesen wir: „In seinem ganzen Leben erweist sich Jesus als unser Vorbild: Er ist der vollkommene Mensch, der uns einlädt, seine Jünger zu werden und ihm nachzufolgen. Durch seinen demütigen Dienst hat er uns ein Beispiel zur Nachahmung gegeben, durch sein Beten regt er uns zum Beten an, durch seine Armut fordert er uns auf, Entbehrung und Verfolgungen bereitwillig auf uns zu nehmen" (Katechismus der Katholischen Kirche 520). Gleichzeitig gilt es zu bedenken, dass unsere moderne Gesellschaft eine Konsumgesellschaft ist, was auch großen Einfluss auf die Kultur der Gegenwart hat. Die Gesellschaft am Übergang vom neunzehnten zum zwanzigsten Jahrhundert wurde als „Produktionsgesellschaft” bezeichnet, in der sich die Industrie entwickelte. Unsere heutige Gesellschaft braucht dagegen die Bürger - als Konsumenten. Deshalb müssen in dem riesigen Supermarkt der Kultur des einundzwanzigsten Jahrhunderts Fähigkeiten erworben werden, um die entsprechende Auswahl treffen zu können. Dazu bedarf es einer spezifischen Wertehierarchie, ein Gefühl für die eigenen Wurzeln, einer Basis und eines geeigneten „Schlüssels”. 
Darum erscheint es nur zu berechtigt, dem Buch „CONTEMPLATIO ET IMITATIO CHRISTI. Chrystologiczny wymiar kontemplacji i naśladowania w duchowości chrześcijańskiej według współczesnego nauczania Kościoła" Aufmerksamkeit zu schenken, in welchem Professor Stanisław Sojka die Ergebnisse seiner wissenschaftlichen Forschungen darlegt. Der Autor ist als Priester und wissenschaftlicher Mitarbeiter an der Theologischen Fakultät, Sektion Tarnów, der Päpstlichen Universität Johannes Paul II. in Krakau, tätig. Gegenstand der hier besprochenen Publikation sind die Kontemplation und die Nachfolge Christi, dargestellt auf Grundlage der gegenwärtigen - nachkonziliären - kirchlichen Lehre, dem Magisterium der Kirche. Dies ist nicht nur berechtigt sondern sogar notwendig, da der Abschluss des Zweiten Vatikanischen Konzils bereits mehr als 40 Jahre zurückliegt. „Die vorliegende Arbeit will sich der gegenwärtigen Lehre der Kirche zum Thema von Kontemplation und Nachfolge Christi nähern. Sie besteht in dem Versuch eine Antwort auf die Frage zu geben: Auf welche Art und Weise weist das Magisterium der Kirche auf die innere Verbindung zwischen diesen beiden Wegen christlicher Geistlichkeit hin?" (S. 19). Denn eine wesentliche Fähigkeit besteht darin, dem Christen von heute wahrhafte und entsprechende Wege für sein Leben aufzuzeigen, insbesondere den bedeutendsten von allen - Jesus Christus, welcher der Weg, die Wahrheit und das Leben ist. Dabei sollen dem Christen Hilfestellungen sowohl für die Kontemplation als auch für die Nachfolge Jesu Christi angeboten werden, die auf der gegenwärtigen Lehre der Kirche basieren, also auf dem Verweis auf die innere Verbindung zwischen diesen beiden Wegen christlicher Geistlichkeit. Es ist besonders hervorzuheben, dass in der rezensierten Publikation die Kontemplation und die Nachfolge Christi in unterschiedlichen Dimensionen der christlichen Geistlichkeit präsentiert und gründlich erörtert wurden, das heißt unter dem Aspekt von Menschen, die ein geweihtes Leben führen, von Priestern und auch von Laien.

Das angebotene Thema der rezensierten Arbeit wurde in drei umfangreiche Kapitel gegliedert. Im ersten Kapitel „Jezus Chrystus - kontemplujący i kontemplowany" (Jesus Christus - kontemplativ betrachtend und betrachtet) ging der Autor sehr ausführlich unter drei Gesichtspunkten auf die Kontemplation ein. Zunächst erörterte er die im Leben Jesu Christi gegenwärtige Kontemplation sowie deren Bedeutung, anschließend die Kontemplation von Jesus Christus, Gott Vater und dem Heiligen Geist. Ebenso zeigte er auf, wie die Kontemplation Jesu Christi durch den Menschen verwirklicht wird. Das zweite Kapitel „Jezus Chrystus - wprowadzający w kontemplację i naśladowanie" (Jesus Christus - er führt zu Kontemplation und Nachfolge hin) charakterisierte, wie Jesus Christus 
in dreifacher geistlicher Hinsicht zu Kontemplation und Nachfolge hinführt: in eucharistischer, marianischer und an die Heiligen gerichteter Ausprägung, dies am Beispiel des Hl. Josef. Dagegen präsentierte St. Sojka im dritten und letzten Kapitel „Jezus Chrystus - kształtujący kontemplację i naśladowanie w poszczególnych stanach życia" (Jesus Christus - er gestaltet Kontemplation und Nachfolge in den einzelnen Lebensformen), wie Jesus Christus die Kontemplation in der Geistlichkeit von Priestern und Menschen, die ein geweihtes Leben führen, ebenso prägt wie bei Laien - dabei ging er in besonderer Weise auf die Geduld Jesu Christi ein. Dies unterstrich der Autor selbst in seiner Einleitung: „Die vorliegende Arbeit greift die signalisierten Anstrengungen in der derzeitigen Situation von Kirche und Welt auf. Vierzig Jahre nach dem Abschluss des Zweiten Vatikanischen Konzils offenbart diese Lage eine pessimistische Sicht auf die Krise in einzelnen Bereichen des menschlichen Lebens, die ganz im Gegensatz zu dem Optimismus steht, der in der Zeit des Konzils erwartet wurde. Viele Anzeichen der gegenwärtigen, insbesondere der europäischen Kultur sprechen dafür, dass sie sich in einem Übergangsstadium befindet: politische und geistige Krisen, Egalitarismus, Terrorismus, Desorientierung, Enttäuschungen und die häufig wiederholte Aussage `Christus ja, Kirche nein'. Dies sind nur einige Aspekte der Krise. Die modernen Kulturinstitutionen sichern dem Menschen keine dauerhafte Konzeption für ein gelungenes Leben zu und lassen Unzufriedenheit entstehen. Davon ist insbesondere die junge Generation betroffen, die sich hoffnungsvoll anderen Kulturen und utopischen Visionen zuwendet, welche die Jugendlichen in den Garten Eden führen, wo Hypnos regiert, indem er sich auf eine Strohmatte gebettet zum Schlaf niederlegt. Die Bemühungen des Menschen, sich von nicht empirischen Sehnsüchten zu befreien, führt ihn hinein in eine Welt der Illusion, wo er in einem hermetischen Raum eingeschlossen und von der normal funktionierenden menschlichen Gesellschaft isoliert ist. Im Prozess der Ablösung von allem Alten und der Suche nach dem Neuen unterscheidet der moderne Mensch die veränderlichen Elemente, die geschichtlichen Denkstrukturen und die Errungenschaften der Menschheit nicht von den unveränderlichen und ewigen Elementen. In dieser von Krisen geschüttelten Zeit des kulturellen Umbruchs ist das Magisterium der Kirche von wesentlicher Bedeutung, da es Werte von überzeitlicher Geltung in sich trägt" (S. 18-19).

In der Struktur derArbeitfinden sich weiterhin das Verzeichnis derAbkürzungen, eine Einleitung sowie ein Schlusswort, die Bibliographie (aufgeteilt in I. Quellen [1. Vor dem Zweiten Vatikanischen Konzil; 2. Während des Zweiten Vatikanischen Konzils; 3. Nach dem Zweiten Vatikanischen Konzil: Paul VI., Johannes Paul I., Johannes Paul II., Katechismus der Katholischen Kirche, Codex des kanonischen 
Rechtes, Glaubenskongregation, Polnische Bischofskonferenz, Kommission des großen Jubiläums]; II. Sekundärliteratur; III. Hilfsliteratur), daneben summary und contents. $\mathrm{Zu}$ betonen ist die immense Menge des gesammelten, geordneten und in die Bibliographie (65 Seiten!) aufgenommenen Materials. Die formale Seite der rezensierten Arbeit ist korrekt. Was den Schreibstil betrifft gibt es in ähnlicher Weise keine größeren Vorbehalte, obwohl die Sprache der Publikation an einigen Stellen für den durchschnittlichen Leser etwas zu kompliziert und verschachtelt ist. Dagegen schmälern einige weniger geglückte Formulierungen in den Schlussfolgerungen und kleinere orthographische oder redaktionelle Fehler ihren Wert nur geringfügig.

Das rezensierte Buch ist gründlich erarbeitet, basiert auf reichhaltigem Quellenmaterial und wendet spezifische Methoden der Textanalyse an. In seiner Ausführung und Präsentation erfüllt es mit Sicherheit die Kriterien einer wissenschaftlichen Abhandlung. Obwohl es sich um eine wissenschaftliche Dissertation handelt, kann die darin aufgegriffene Problematik wie auch die Art ihrer Präsentation neben den darauf spezialisierten Experten wahrscheinlich auch einen größeren Leserkreis ansprechen. Der ordnende Grundsatz und die abgegebenen Einschätzungen zeugen vom Objektivismus und vom richtigen Maß des Autors. Zusammenfassend ist diese Arbeit ein reifes Werk, das einen weiten Bereich an Material umfasst und gewissenhaft zusammengestellt ist, was sowohl in der Gesamtschau als in redaktionellen Einzelheiten ersichtlich wird. 